\title{
DEL FRACASO A LA AURORA: LOS ORÍGENES SOMBRÍOS DEL SABER
}

\author{
From Failure to Aurora: The Dark Origins of Knowledge \\ Lorena ROJAS PARMA ${ }^{1}$ \\ Universidad Católica Andrés Bello (Caracas, Venezuela)
}

\section{Resumen}

El artículo se propone una disertación sobre la experiencia del fracaso en tres direcciones: i) la tendencia a la negación u ocultamiento de lo padecido, y sus consecuencias; ii) las posibilidades de su comprensión y la ocasión que implica una experiencia tan exigente para comprometer el auto conocimiento y la posibilidad misma de la filosofía; iii) el asombro (thaumazein), considerado ahora desde la perspectiva del fracaso, exige una reflexión sobre la propia condición que, bajo la imagen de la «Aurora», supone una posibilidad hacia el «conócete a ti mismo» y los inicios del filosofar.

Palabras clave: fracaso, ocultamiento, episteme, Aurora

\section{Abstract}

This article proposes a study on Failure. It will consider: i) The painful experiences we try to hide and deny and its consequences; ii) How we can understand Failure and how it is an opportunity to self knowledge and the possibility of philosophy; iii) Amazement (thaumazein), considered from the experience of Failure, demands a reflection of that experience and using «Aurora» as an image, it represents a possibility towards nosce te ipsum and the beginnings of philosophy.

Key words: failiure, hide, episteme, Aurora

1 Profesora e investigadora en la Escuela de Filosofía de la U.C. Andrés Bello de Caracas (Venezuela). Correo electrónico: lorojas@ucab.edu.ve. Fecha de recepción del artículo: 24 de septiembre de 2015. Fecha de aceptación: 27 de noviembre de 2015. Versión final: 27 de agosto de 2016. 
Cuando ponías tu marca en mi frente, jamás pensé en el mensaje que traías, más precioso que todos los triunfos.

Rafael Cadenas, Fracaso ${ }^{2}$

\section{Proemio. «La oscuridad guarda un Carácter VENERABLE», DIONISO}

Cuando los griegos intuyeron la naturaleza trágica de la existencia, cuando concibieron dioses de la noche, de culto en los montes, fuera de la urbe luminosa de Apolo y Atenea, le dieron permiso a lo oscuro para que revelara la verdad de sus almas; para que fuera parte de ellas y las constituyera en un sentido profundo y completo. Sabemos que incluso el esplendoroso Apolo, dueño del intelecto y el acierto, del sol que todo descubre, guarda en su divinidad una manía maravillosa desde la que dirige el coro de las musas y adivina la vida de los que van a Delfos en busca de una respuesta. Hoy reconocemos, sin grandes dificultades, que nunca estuvo muy lejos de Dioniso. ${ }^{3}$ Fueron los dioses y la tragedia quienes nos advirtieron, con una agudeza que no deja de conmovernos, que lo que se oculta o se niega no se debilita. Por el contrario, regresa fortalecido y hasta con aires vengativos, como solía volver Dioniso; dios nocturno y extraño, desatador implacable de tristezas y vergüenzas, que no nos gusta reconocer.

$\mathrm{La}$ «lucha» con este dios, sin embargo, que no soporta estar escondido y no ser reconocido como dios, es intemporal. El suspiro por una existencia sin fracturas es igual de antiguo; como lo es no querer enfrentar la pena y el dolor. Con todo, la tragedia tuvo el ímpetu de mostrar este drama en el teatro mientras afectaba a todos sus espectadores; al menos entonces el dolor del alma, y en sus versiones muy crueles, tuvo un espacio público donde reclamar sus derechos. Pero la eternidad de Dioniso radica precisamente en su inagotable exigencia de reconocimiento, $y$ en nuestra resistencia a reconocerlo como una fuerza que tiene el poder de doblegarnos mientras nos recuerda nuestra fragilidad, nuestra condición de mortales. ${ }^{4}$

2 R. Cadenas, Poemas Selectos, Caracas, Bid \& co., 2009, p. 43.

3 G. Colli, El nacimiento de la filosofía, Barcelona, Tusquets, 2000, pp. 9-87.

4 Eurípides, Bacantes, Madrid, Gredos, 1982, vv 865-1390; Apolodoro, Biblioteca mitológica, Madrid, Alianza, 1999, libros II-III; Th. Carpenter y Ch. Faraone (comps.), Masks of Dionysus, Cornell University Press, 1993: 13-146; M. Detienne, Dioniso a cielo abierto, Barcelona, Gedisa, 1997: 15-85; M. Detienne, Dionysos mis à mort, Gallimard, Saint- 
Eso que sentimos opaco, nocturno en nosotros, lo identificamos también con lo doloroso, reconocemos la dificultad de integrarlo y, en el mejor de los casos, reinterpretarlo. Cuando lo negamos o lo escondemos, lo hacemos porque nos duele hasta la entraña y, en nuestro intento heroico por evadirlo, solemos no darle la cara, no incorporarlo a la vida, mientras simulamos ante nosotros mismos que ésta sigue en su recorrido como si tales experiencias no la afectaran. Ese ignorar la pena es especialmente grave cuando lo hacemos en nuestra intimidad, en medio del hacer del alma que se «ocupa en sí misma» (botan aute kath' auten pragmatenetai peri ta onta), como decía Platón. ${ }^{5}$ Y si renunciamos a la cavilación y al pensamiento, quedamos atrapados en una superficialidad que a duras penas oculta el pesar y trivializa la vida. Esa ligereza es un falso alivio que nunca alcanza los fondos vitales. A veces, al menos, no es saludable que esas experiencias opacas sólo respiren en nuestra vida secreta. A veces se sofocan en nuestros territorios subterráneos, afectándonos la vida de otras formas, incluso a espaldas nuestras. Sin embargo, experiencias de esta naturaleza quizá no puedan ser ni remotamente enumeradas o clasificadas, y probablemente puedan ser «medidas» sólo por la manera cómo nos tocó vivirlas, al viejo modo del anthropos metron de Protágoras. En esta ocasión, haré referencia sólo a una de esas verdades no luminosas por las que solemos atravesar: el fracaso.

Esa inclinación a sepultar una experiencia tan dolorosa, para no verla, para evitar su pena, suele tener la intención de debilitarla en el inframundo del olvido. Y sin detenernos ahora en que el olvido guarda algunos secretos temporalmente, quiero insistir en la imagen extrema de la sepultura, donde quisiéramos enterrar, en última instancia, las ruinas tormentosas de algo acontecido. Pero con esto ocurre algo peligroso: olvidamos que el sepulcro es para el muerto, y cuando enviamos el fracaso no trabajado por el espíritu a esos subsuelos, no llega sin vida. Lo sofocamos en esas honduras, pero no suele morir. Y entonces nuestra pesadilla es descubrir, finalmente, que los intentos por disipar la experiencia del fracaso confinándolo al sepulcro, son inútiles. Probablemente la sabiduría profunda de la trage-

Amand (Cher), 1998: 49-99; K. Kerényi, Dionisos, raíz de la vida indestructible, Barcelona, Herder, 1998: 99-137 y 191-265; W. Otto, Dioniso, mito y culto, Madrid, Siruela, 1997; 63-67; 78-99; y 138-153; R. López-Pedraza, Dionisos en el exilio, Caracas, Festina lente, 2000 , p. 71 y ss.

5 Platón, Teeteto, 187a. La versión griega utilizada para los diálogos platónicos es Platonis Opera, J. Burnet, Clarendon, Oxford University Press, 1973. Tomos I-III. Para las versiones españolas autorizadas, $c f r$. bibliografía, pp. 26-27. 
dia sugiera que lo terrible de lo sucedido, se enfrente, se padezca con toda su conmoción, y sin resistencia sintamos el quiebre del espíritu y de la vida cuando nos toca perder. Ese regreso del encierro, como nos enseñó Dioniso, suele ser aún más penoso. Esa es la dinámica del dios: más negación, regreso más furioso y contundente. El destino de Penteo, en Bacantes, nos lo muestra de la manera más despiadada posible. ${ }^{6}$

Desde esta mirada, en las próximas líneas, trataré de disertar sobre el fracaso y su importante lugar en la vida. Sobre su momento de oscuridad, ciertamente, pero también sobre la resurrección que nos permite si nos hemos rendido ante la experiencia, la hemos aceptado y no la bemos ocultado en nuestros suburbios. Por tanto, esta breve meditación no es una oda al fracaso o a una vida desde el dolor. En realidad, se trata de considerar esa experiencia oscura como la ocasión en la que es posible un hallazgo que comprometa sensiblemente la auto comprensión, de convertir ese «dolor aplastante» en un regreso hacia nosotros mismos, como decía Schopenhauer, para volver por encima de todo sufrimiento. ${ }^{7}$ De esta manera, esas fracturas del fracaso, con su padecer, también pueden llevarnos por el camino espinoso del antiguo «conócete a ti mismo».

Con esto quiero decir que el reconocimiento y aceptación del fracaso pueden traer consigo la bondad de re-conducirnos, de hacernos más conscientes de nosotros mismos, más compasivos, y llevarnos, con el tempo que precise, con la elaboración de alma que se requiera, a nuestra «propia Aurora", como bellamente dijo Nietzsche recordando el Rig Veda. Así, pensar el fracaso ha de permitirnos, también, una cavilación sobre nuestra propia Aurora. Tras la noche oscura y antes del triunfo del sol, aparece el extraño intermedio, al modo del no menos extraño metaxy platónico, del que hablaremos más adelante, donde los opuestos misteriosamente se encuentran, se serenan y se comunican, y que ahora nombramos Aurora.

\section{LA «NOCHE OSCURA DEL ALMA»}

Si el ser se dice de muchas maneras, como dijo el filósofo, el fracaso también. No obstante, ese decir sólo es posible desde la experiencia de cada uno, desde su intimidad, desde el fondo donde se ha sentido el quiebre,

6 Cfr. vv. 1020-1390; R. Schlesier, «Maenads as Tragic Models», en Th. Carpenter y Ch. Faraone (comps.), Masks of Dionysus, Cornell University Press, 1993: 89-115.

7 A. Schopenhauer, Los dolores del mundo, Buenos Aires, Prometeo, 2013: 53. 
desde donde somos la medida de lo que juzgamos un fracaso. Medida en el sentido de Protágoras: desde su sensación, su juicio, su padecer (aisthesis). ${ }^{8}$ Cada uno sabe a qué llamar fracaso; cada uno sabe, con sabor de sangre y lágrimas, a qué darle ese nombre. El hombre es la medida de lo que padece desde su aisthesis, palabra que suele traducirse como "percepción», pero que aún para Protágoras implica en su significación la emoción y la razón, el logos y el pathos, la intervención de la sensibilidad, sin delimitaciones o fracturas entre ellos; ' de manera que lo sucedido es para él una afección evidente que, en tanto tal, no requiere ser «probada». Nadie puede negarnos nuestra aisthesis, lo que juzgamos y sentimos evidente, aunque otro no sea testigo de esa misma evidencia. De esa naturaleza se nos presenta la experiencia del fracaso, siempre referida a nosotros, siempre en relación con algo de la realidad que ha permitido esa experiencia. ${ }^{10}$ Las aistheseis suponen, para Protágoras, una correlación entre la sensibilidad del homo mensura y lo que le afecta del mundo. Y el resultado de esa correlación es una noción de verdad que se sostiene en la propia experiencia entre las sensaciones y lo real. Por tanto, no estamos ante un Sócrates exigiendo implacable una definición de lo que se padece o se siente fracaso; ahora no estamos en medio del diálogo socrático que con sus exorcismos de falsa doxa, probablemente serenaría nuestra emocionalidad desorientada. Nos mantenemos en los linderos de la experiencia, de lo sentido, de la afectación que hemos recibido de la physis, que cuando se encuentra con nuestra sensibilidad, dice Protágoras, devela un acontecimiento. ${ }^{11}$ En este sentido es posible afirmar que el homo mensura sabe a qué llamar fracaso -que es lo que ahora nos ocupa- y estaría en condición de saberlo desde su contundente y polémica afirmación aisthesis es episteme. ${ }^{12}$ Lo que significa que la

8 Hago referencia, por supuesto, al homo mensura, $c f r$. Teeteto, 152a y ss., Sexto Empírico, Esbozos pirrónicos, I, 216 y ss.; A. Melero, Sofistas, testimonios y fragmentos, Madrid, Gredos, 1996.

9 Cfr. Á. Cappelletti, Protágoras, naturaleza y cultura, Caracas, Biblioteca nacional de la historia, 1987: 87-88; F. Cornford, La teoría platónica del conocimiento, Barcelona, Paidós, 1992, pp. 43-44; H.-G. Gadamer, El inicio de la sabiduría, Barcelona, Paidós, 2001: 119-120; J. Mansfeld, "Protagoras on Epistemological Obstacles and Persons», en G. Kerferd (comp.), The sophists and their legacy..., 1981: 44 y ss.; A. E. Taylor, Plato, the Man and his Work, New York, Meridian Books, 1959, p. 325, n. 3; L. Rojas-Parma, «Acerca de aisthesis en el Teeteto de Platón», Apuntes, 27 (2005); L. Rojas-Parma, «Protágoras y el significado de aisthesis», Revista de Filosofía, 71 (2015): 127-149.

10 Tal es la relación que Sexto expone sobre la posibilidad de la episteme en Protágoras. Cfr. Contra profesores VII: 60-63.

11 Esbozos pirrónicos, I, 216 y ss.; M. Untersteiner, I sofisti, Milano, L. Negri, 1967, p. 43.

12 Platón, Teeteto, 151e. 
episteme no deja de estar intervenida, entonces, por emociones, cambios, disposiciones del cuerpo y la fragilidad de lo humano; en fin, que nunca abandona los tejidos de la vida.

Sabemos que la aisthesis en ningún caso es falsa, pero tampoco es eterna. Es tan fluyente como nosotros y como el mundo. Pero, mientras dure, es lo que creemos o sentimos. No en vano Protágoras, desde su habilidad con la palabra, decía que el sabio era el que lograba convertir lo malo en algo que pareciera y fuera bueno, ${ }^{13}$ sin sostener que esa aisthesis «mala» fuese falsa. ${ }^{14}$ Con la consecuente tranquilidad de alma que tal conversión que ocurría en uno, traía consigo. En este sentido, el contrincante de Sócrates nos auxilia con su noción aisthesis, con la sensibilidad que aún es también juicio, que nos hace posible nombrar lo padecido como fracaso, y nos permite disertar sobre él. Desde esta perspectiva, el saber de la vida adquiere una condición más estética, pues se lo concibe pleno de su apasionamiento, de la enfermedad, del dolor, del amor, en relación profunda con lo que el mundo le manifiesta a cada uno según su sensibilidad, y sin hacer del logos el tribunal último que se pronuncia ante un acontecimiento que nos ha estremecido. Así, si esto es episteme, como sostenía Protágoras, el conocimiento nunca se apartó de la vida con sus aciertos y sus tristezas. Y a este saber tan particular quiero recurrir para hablar de nuestro saber del fracaso, del saber que lo estamos padeciendo, para poder aceptarlo y hacer nuestro trabajo de transformación que, eventualmente, nos llevará hacia las horas de la Aurora.

Una episteme de esta naturaleza es completamente distante de Sócrates, Platón o Aristóteles. Y de la tradición. Sin embargo, no es esta larguísima polémica - podríamos comenzar por la graves discusiones de Platón- ${ }^{15}$ la que ahora nos ocupa. Sí, por el contrario, la contundencia que Protágoras reconoce a la experiencia y la potente afirmación del hombre como medida de verdad de lo que le acontece. Con la humildad de aceptar lo frágil de la propia sensibilidad, que en unos casos se afecta por unas cosas, y en otras, por otras. Y lo que afecta mi sensibilidad, no necesariamente afecta a la de otro. El homo mensura no aplica para un hombre privilegiado; es cada uno de nosotros. ${ }^{16}$ Así, creo que para aproximarnos a algo tan difícil como el

13 Platón, Teeteto, $166 \mathrm{~d}$ y ss.

14 En ningún caso la aisthesis podría ser falsa. El hombre es la medida, y «¿̨no somos tú y yo hombres?» (cfr. Teeteto, 152a). Y Teeteto, 166d-167d.

15 Platón, Teeteto, 161a y ss.; y 170a y ss.

16 Platón, Teeteto, 151e; E. Dupréel, Les sophistes, Neichatel, 1948, y su interpretación sociológica del homo mensura; J. Barro, «El pensamiento de Protágoras» en Protágoras y 
fracaso, esta manera de asumir al hombre puede ser de nuestra ayuda. Dejemos que cada uno sea su propia medida en un asunto tan sensible, con su logos y su corazón. Con todo, Sócrates vendrá oportunamente a recordarnos que esa fragilidad de las aitheseis, de las opiniones cambiantes y fluyentes, exigen un examen riguroso en el que se aspira al hallazgo de algo verdadero, racionalmente fundado. Protágoras nos permite aceptar la experiencia, tal y como se nos aparece; Sócrates, su examen. Ambos, y esto es ahora lo importante, la naturaleza fluyente de la experiencia y lo acontecido — con pretensiones de «verdad» sólo para el sofista.

Sabemos que decir fracaso, es decir ruina, caída, revés, ruptura, decepción y todas esas palabras que guardan sus «aires de familia». No tengo intención, por lo antes dicho, de sugerir una «definición» de fracaso. Es una experiencia tan íntima y, así, tan universal como el que la padece. Ocurre con esta palabra, como con muchas otras, quizá con todas, lo que a San Agustín con la palabra «tiempo» — anécdota muy conocida, pero oportuna: dice que sólo la comprende cuando la usa, esto es, cuando la dice y cuando la escucha. Pero cuando le piden que la defina, la respuesta es nescio, "no sé». ${ }^{17}$ Pero Wittgenstein, quince siglos después, con su agudeza terapéutica, respondió: con el uso era suficiente; no era necesario averiguar nada nuevo, sino darnos cuenta de lo que tenemos frente a nosotros. ${ }^{18}$ En este sentido, si ahora diserto sobre el fracaso, cada uno comprende lo que digo y seguramente remueve de su propio fango algo desagradable con sabor a fracaso. Hay cosas, experiencias, que tienen sabor más que definiciones, y hago alusión, por supuesto, a la relación profunda entre sabor y saber. Tan sólo recordemos que sapere significaba «tener y ejercer el sentido del gusto", «tener tal o cual sabor». ${ }^{19}$ «Saber» llevaba consigo «sabor». En realidad, nada nos engaña con su sabor; y así sabemos las cosas. Es inevitable hacer el vínculo espiritual —no filológico— con lo que Martha Nussbaum llama la episteme del

Gorgias, testimonios y fragmentos, Barcelona, Orbis, 1980, pp. 20 y ss. Sobre la implicación individual y social del homo mensura, y la imposibilidad de separarlas, cfr. L. RojasParma, «De la polis, la tradición y el buen juicio: el ciudadano democrático de Protágoras», Cuadernos UCAB, 9 (2011).

17 «Quid autem familiarius et notius in loquendo commemoramus quam tempus? Et intellegimus utique, cum id loquimur, intellegimus etiam, cum alio loquente id audimus. Quid est ergo tempus? Si nemo ex me quaerat, scio; si quaerenti explicare velim, nescio». Confesiones, XI, 14.

18 Investigaciones filosóficas, parágrafos, 89-90.

19 J. Corominas, Diccionario etimológico de la lengua castellana, Madrid, Gredos, 1973. 
ser amado, ${ }^{20}$ a propósito de la queja embriagada de Alcibíades contra Sócrates, la noche del Banquete, cuando lamentaba el desplante de su amante que hizo imposible la adquisición de ese saber, que también era sabor. En efecto, la episteme del amado sabe, se sabe. Desde esta hermandad del saber y el sabor, puedo aludir de nuevo a la aisthesis de Protágoras, a aquella significación arcaica de la palabra, que aún no desgarraba la unidad de lo sentido o percibido en logos y pathos, que hacía posible el saber con toda la dulzura o amargura de lo vivido. Y esto es importante porque estamos hablando del fracaso. ${ }^{21}$ Aisthesis era episteme. Y si con aisthesis el saber de la vida se tornaba más estético, con sapere se descubre profundamente erótico. Saborear es saber. Y el saber algo estremece todos los espacios corporales y espirituales del gusto, que sabe de una manera indiscutible y contundente. ${ }^{22}$ El deseo anuncia el sabor, y el deseo es lo que nos mueve hacia el saber, como nos lo recuerda Sócrates. ${ }^{23} \mathrm{El}$ «sabor a mí» del bolero, de más de «mil años muchos más», es, por supuesto, saber de mí.

Pero ya es tiempo de comenzar a atravesar nuestra noche oscura. Para ello, y teniendo en cuenta este saber, quizá sea oportuno recordar algunas líneas de De profundis, de Oscar Wilde, texto oscuro como el fracaso y transformador como el más cruel de los procesos que atraviesa un alma con fe. En el fondo del más oprobioso encierro, escribe el poeta: «Donde hay pesar, hay tierra sagrada debajo». ${ }^{24} \mathrm{Y}$ con esta verdad sin concesiones, inquieta la imagen del sepulcro: lo que «está debajo», lo que da raíz al dolor que se padece, es lo sagrado. La pena que no se oculta se revela como el fruto de una tierra sagrada. Y entonces resulta aún más terrible pensar en esa inclinación a no encarar el dolor del fracaso; y si no a enterrarlo, a disfrazarlo de evasivas, de ilusiones forzadas, y a no ver el profundo sentido religioso que se devela con el dolor. Así, el pesar luce como el gesto, como la insinuación de lo sagrado de uno que sale a luz gracias al horror de lo vivido. Bien decía Ifigenia: «Nadie sabe a quién le espera un destino así. Todo lo divino camina en la oscuridad... $»^{25}$ Las palabras del poeta nos

20 M. Nussbaum, La fragilidad del bien, Madrid, Visor, 1995, pp. 258-259.

21 «Entonces la pregunta no es: ¿qué quiere decir esta palabra?, ¿cómo puedo precisar su significado?, sino: ¿dónde la pongo, cómo puedo situarla en mi vida, en mi historia, cómo reconocerla? Tengo que interrogar mi paladar (mi deseo) hasta saber de qué tengo hambre», M. F. Palacios, Sabor y saber de la lengua, Caracas, Monteávila, 1984, p. 29.

22 H.-G. Gadamer, Verdad y método, Barcelona, Sígueme, p. 68.

23 Cfr. Platón, Banquete, 210a y ss.

24 O. Wilde, De Profundis, Obras completas, Madrid, Santillana, 2004, p. 523.

25 Eurípides, Ifigenia entre los tauros, vv. 475. 
ponen frente a la situación en la que el dolor ya no se ignora, en la que el fracaso se hace carne y des-cubre el fondo secreto de algo atesorado en nosotros como la misma divinidad. Y nos damos cuenta que lo que lloramos es nuestro propio santuario. Amoroso y profundo, lastimado y decepcionado. Creo que esa tierra sagrada secretamente nos sostiene, nos embellece, y sólo sabemos de ella cuando la pena ha encontrado nicho en nosotros. Dice el poeta que «el dolor es lo más sensible de la creación. Nada existe en el mundo del pensamiento a que no responda el dolor con su latido». ${ }^{26} \mathrm{El}$ mundo del pensamiento que aún no ha sido exorcizado de emociones y corazón, nunca es tan árido como para no sentir ese latido que nos revela en un sentido complejo. Si sepultamos el dolor del fracaso, aterrorizados por lo ocurrido, enterramos en vida lo que exigía ser reconocido y acogido, devuelto a la luz, para cumplir alguna tarea que puede ser de regreso a uno mismo, haciendo posible una transformación interior. ${ }^{27}$ Así, sepultar el dolor que nos provoca un fracaso, es lo que termina cavando nuestro propio sepulcro.

Dice López Pedraza que «cuanto concierne al fracaso está fuertemente reprimido, como si fuera lo último de lo que nos quisiéramos enterar». ${ }^{28} \mathrm{Y}$ probablemente sea lo último de lo que queremos hablar. Por supuesto que el fracaso implica su contrario: el triunfo. Y aunque de este sí nos guste hablar, no es lo que ahora concentra estas cavilaciones; en realidad, me interesa la experiencia del fracaso y su lugar en la vida, más que darle fuerza desde su oposición al éxito. Desde antiguo sabemos que la bybris del triunfo nos enceguece al punto mortal de no ver su reverso.

Generalmente no contamos con los recursos espirituales para enfrentar una caída estrepitosa como la de un fracaso. Y si ahora acuso la tendencia al sepulcro, a alguna manera creativa de no aceptación, no digo que sea incomprensible. El fracaso es como un descenso violento y horrible hacia un fondo desconocido de nosotros mismos, donde sentimos que no hay un solo dios que nos asista. Es una caída a un suburbio al que jamás hubiéramos querido ir, pero que parece que nos esperaba; con una atmósfera de desamparo, de olvido del kosmos, donde el sabor de la existencia es amargo, y cuando la frase «toda vida es esencialmente dolor» de Schopenhauer, adquiere un significado aún más contundente. ${ }^{29}$

26 Op. cit., p. 522.

27 Schopenhauer, 2013, op. cit., p. 54.

28 R. López Pedraza, Ansiedad cultural, Caracas, Festina lente, 2000, p. 95.

29 Op. cit., p. 35. 
Sin embargo, en esos fangos terribles, hay que aprender. Hay que «hacer alma» de la mano de la reflexión y del asombro por lo ocurrido: el fracaso no deja de tener ese halo de lo inesperado. Y si hay asombro, ha de haber Eros, pues sólo se asombra el que ama..$^{30} \mathrm{Y}$, entonces, desde ese fondo, también nos topamos con la filosofía, pues algo de nosotros se revela y exige ser pensado. Todo nos devuelve, una vez más, al lugar de siempre: a Heráclito diciendo "me investigué a sí mismo», ${ }^{31}$ a la interioridad que halló Sócrates y al gnothi seauton que viene de Delfos, ${ }^{32}$ a Hobbes recordándolo como nosce teimpum, ${ }^{33}$ a los filósofos volviendo sus miradas reflexivas de maneras diversas hacia sí mismos. Ahora lo pensamos en medio de una experiencia muy penosa, es cierto, pero allí está el momento del quiebre, una posibilidad de redención y de transformación. Y aunque hable de fango y suburbios, en esos fondos de la pena, como ha dicho el poeta, se haya nuestra «tierra sagrada». La Aurora de Nietzsche llegó tras un oscuro trabajo y una larga privación de aire y luz. ${ }^{34}$ En medio del lugar desagradable al que nos arroja el fracaso, nos hallamos desorientados, adoloridos, pero abrumados por el asombro de lo ocurrido. Desnudos de virtudes y, por ello, asombrados. Una voz extraña como la del daimon, él mismo conmovido, pregunta: «¿qué es esto?». Y si tenemos la disposición reflexiva, si somos capaces de la mirada interior, desde ese asombro oscuro, animado ahora por un Eros desmesurado como el de Sófocles ${ }^{35}$ o el «enfermo» del

30 M. Cruz, Amo, luego existo, Buenos Aires, Eudeba, 2013, p. 14. Hillman nos recuerda el uso de aisthesis, al que aún se acoge Protágoras, para acentuar su significación originaria de «... inspiración, ese asumir, ese quedarse sin aliento, esa exclamación que produce el asombro ante las maravillas del mundo: una respuesta estética ante la imagen (eidolon) que se nos presenta», J. Hillman, El pensamiento del corazón, Madrid, Siruela, 2005, p. 155. Todo lo que implica aisthesis, con el centro sensitivo en el corazón y la capacidad de asombrase, también ocurre en medio de una vorágine ocasionada por un fracaso. Y si atravesamos la noche de ese desierto con éxito, y vislumbramos la Aurora, quizá no veamos lo ocurrido como una de las «maravillas del mundo», es cierto, pero sabremos secretos de nosotros ante los que quedamos sin aliento y asombrados. Desde la aisthesis nuestra respuesta es estética, gracias al saber propio que se ha comprometido y que nunca abandonó el corazón.

31 Edizesamen emeouton, frag. 101. M. Markovich, Heraclitus, editio minor, Mérida, ULA, 1968, p. 31. La traducción de esta edición: «Me pregunté (dirigí) a mí mismo».

32 M. García-Baró, De Homero a Sócrates, Salamanca, Sígueme: 193-194; J. Humbert, Sócrates y los socráticos menores, Caracas, MonteÁvila, 1995, p. 84; J. Patočka, Platón y Europa, Barcelona, Península, 1991, p. 84.

33 «There is a saying much usurped of late, that wisdom is acquired, not by reading books, but of men», T. Hobbes, Leviathan, Fontana, William Collins, 1978, p. 59.

34 F. Nietszche, Aurora, México, Editores mexicanos unidos, 1981, p. 5.

35 Sófocles, Antígona, 781-798 B. 
Erixímaco platónico, ${ }^{36}$ también comienza la filosofía. Allí hacemos la pregunta y contemplamos; algo exige ser pensado. Allí la «llama purificadora del dolor» de Schopenhauer, ${ }^{37}$ enciende una chispa. Con «temor y temblor» también nos recibe el pensamiento.

López Pedraza habla de la necesidad de hacer "conciencia del fracaso», ${ }^{38}$ y esto implica tomar distancia, silencio, tempo, para la reflexión. Detenerse ante el asombro. Abrazar la oscuridad de la experiencia, y hacer en nosotros los descubrimientos a los que hemos sido convocados. Si nos conectamos con ese proceso reflexivo, teñido por la extrañeza, comenzamos a dar sentido a lo sucedido, a descubrir la pregunta, a trazarnos un nuevo camino interior. Y en ese diálogo interno hallamos el Eros que anima toda comprensión: «El mirar que puede proporcionarme un ver no es el aséptico contemplar vivencialista, sino el único capaz de dotar de forma a lo mirado: el de la mirada erótica». Con estas palabras, Luri se refiere a la mirada que damos al otro, y a cómo nos articulamos ante él; sin embargo, ese mismo mirar erótico es el que hace posible también la propia lectura, el hallazgo de sentido en nosotros, cuando estamos desorientados o abrumados por el asombro. «La tensión erótica imposibilita el nihilismo hermenéutico - continúa el autor-, es decir, la disgregación del alma en una pluralidad subjetiva de vivencias». ${ }^{39}$ Lo erótico tensa, concentra, da sentido, da forma. Evita, efectivamente, que nos dispersemos de nosotros mismos, que nos disgreguemos como las estatuas de Dédalo, ${ }^{40} \mathrm{y}$ se haga imposible el pensamiento. Es la disgregación interior como evasión, como un perderse en lo diverso evitando cualquier acto de conciencia. Esa evasión la detiene Sócrates, por supuesto, con su exigente pregunta en el diálogo, ${ }^{41}$ pero también la impide Protágoras, con su aisthesis, a la que con dificultad nos resistimos, porque compromete toda nuestra sensibilidad. Y eso que debemos confrontar es precisamente lo que ha de ser convertido en algo que «parezca y sea bueno».

En opinión de López, un componente psicopático, la histeria y el puer eternus son los elementos de la naturaleza humana que, por tener como rasgo dominante la aceleración, hacen imposible todo ese proceso inte-

36 Platón, Banquete, 186b.

37 Op. cit., p. 53.

38 Op. cit., p. 95.

39 G. Luri, El proceso de Sócrates, Madrid, Trotta, 1998, p. 47.

40 Menón, $98 \mathrm{~d}$.

41 Cfr. por ejemplo, Platón, Teeteto, 169a-b. 
rior. ${ }^{42}$ Como consecuencia, la superficialidad toma por asalto el lugar donde ha debido horadarse la tierra sagrada, cargada del Eros que nos vitaliza incluso desde su aspecto más cruel. En su lugar, aparecen escapatorias tontas, histrionismos, amargura, reemplazos que entorpecen el pensamiento y la emoción, mientras emerge una silueta que recuerda al amante «cuadrúpedo» (tetrápodos) del que habla Platón, ${ }^{43}$ ahogado en la vida mediocre de lo disperso y tan capaz de amar lo bello como un animal. Ahora no contamos con el espacio para disertar sobre esos elementos acelerados de los que habla López que nos ciegan a la reflexión. Pero sí traigo al texto unas líneas que describen el drama en el que podemos encerrarnos si no hacemos «conciencia del fracaso»:

Cuando sucede una caída de la cual aprender y reflexionar, rebotamos rápidamente asidos a otra fantasía vaporosa, que irremediablemente nos lleva al encuentro de otro fracaso; pues lo que posiblemente nos prevendría de nuevos fracasos es hacer conciencia de ello. Pero no, la demanda de triunfo es tan avasalladora que no nos provee del tiempo ni del tempo que hacen posible la reflexión. La demanda de triunfo hecha complejo autónomo nos impele a la repetición. ${ }^{44}$

En lugar del cultivo de la tierra sagrada que devela el dolor, de vivir la experiencia del asombro, «rebotamos». La imagen sugiere que no nos demoramos en absoluto en lo sucedido. El miedo a encontrarnos con la pena, con lo que no logramos integrar porque parece que desmorona nuestra identidad, hace que nos sostengamos de alguna «fantasía vaporosa» que luce como un milagro tranquilizador y anestésico. Ese ensueño puede aparecerse como una compensación, un merecido acto de justicia tras lo sucedido que queremos enterrar en el olvido. Esas son «trampas» en las que decidimos enredarnos. López anuncia un próximo y seguro fracaso; y no creo que alguien lo dude. Y no sólo por la necesidad triunfalista que, en efecto, nos agobia, sino por la tremenda dificultad de asumir lo acontecido desde la idea —otra «fantasía»- que tenemos sobre nosotros mismos, sobre lo que creemos que somos.

Eso nos conecta con las andanzas de Sócrates por Atenas preguntando a todos por su vida, exigiéndoles que dieran cuenta de cómo viven, ${ }^{45} \mathrm{y}$

42 Op. cit., p. 102.

43 Platón, Fedro, 250e.

44 Op. cit., pp. 98-99.

45 Platón, Apología de Sócrates, 29d-30a; Ión, 533d; 540a-542a; Hipias mayor, 287d-e; 298bc; 301a-302b; 304a-e; Laques, 191a-193e; 195a; Protágoras, 329b-d; 360d y ss. 
mostrando a sus interlocutores que realmente no saben lo que creen que saben, ni son lo que creen que son. ${ }^{46}$ En efecto, si lo que creemos de nosotros lo asumimos como algo sólido e incuestionable, no estaremos en disposición de "examinarnos», de volcar la mirada hacia nosotros y mucho menos en condiciones de soportar un fracaso. Sin embargo, Sócrates nos enseñó que las complejas búsquedas filosóficas en diálogo pasan por un fuerte proceso de renuncia a lo que hemos creído de nosotros y de las cosas; que lo atesorado como «verdadero» en nuestras almas queda expuesto y derrotado en ese proceso dialéctico que ha de cumplir la misión de exorcizar nuestra falsa doxa. Así, el fracaso de nuestras opiniones, el quedarnos sin nada, es parte de lo que nos prepara para iniciar la búsqueda de lo - auténticamente- verdadero. ${ }^{47}$ No en vano este hacer de Sócrates se llama «mayéutica». Con la aceptación y entrega ante la evidencia de que no sabemos lo que creíamos que sabíamos, aceptaremos que no somos lo que creíamos que éramos y que, por lo tanto, nuestras creencias nunca fueron firmes ni invariables. Si bien Sócrates dirige sus búsquedas hacia lo estable, por el camino (methodos) va mostrándonos cuan cambiantes y frágiles son nuestras doxai cuando se las enfrenta. Probablemente Sócrates sea el último que nos permita alguna pretensión triunfalista. El político de Apología, Laques, Calicles, Trasímaco y hasta Alcibíades son algunos ejemplos de ello. Padecer el fracaso quizá sea importante para apaciguar esos vapores fantasiosos que nos hacen creer lo que no sabemos ni somos - a menos que non resistamos a hacerlo, como Alcibíades. ${ }^{48}$ Quizá ese padecer nos haga más humildes y, así, con más posibilidades de hacer hallazgos en nosotros mismos de la mano de Sócrates.

En este sentido, quiero enfatizar la condición cambiante de nuestras creencias y presuntos saberes, y la conciencia que probablemente haga menos dramática la experiencia del fracaso. Si no confundimos la firmeza de la episteme socrática con lo que creemos que somos, ${ }^{49} \mathrm{un}$ fracaso no podría

46 Platón, Apología de Sócrates, 21c-e; 23 a-c.

47 Esto es, aquello que es racionalmente fundamentado. Cfr. C. Eggers, El sol, la línea y la caverna, Buenos Aires, Colihue: 86-88; Nussbaum, 1995, p. 259. Cfr. Ión, 542a y ss.; Eutifrón, 6e y ss.

48 Platón, Banquete, 216a-c.

49 Esto es importante: lo que muestran Calicles, Polo o Trasímaco, por ejemplo, es la firmeza y la solidez que adjudican a sus convicciones «no examinadas» — no, al menos, socráticamente- y que asumen como verdaderas, mientras se indisponen cuando se someten a discusión - actitud frecuente en el que no sabe cómo fundamentar su convicción. Esa imagen que nos hacemos de nosotros mismos, hecha de creencias que hemos recibido 
devastar dolorosamente alguna «fantasía» sobre nosotros. El «conócete a ti mismo» de Apolo pero también de Sócrates, nos protegería, por así decirlo, de una destrucción muy penosa de alguna imagen que hayamos construido a espaldas nuestras. Diotima sostuvo que «nunca somos los mismos ni siquiera en relación con los conocimientos». ${ }^{50} \mathrm{Y}$ que nuestros «hábitos, caracteres, opiniones, deseos, placeres, tristezas, temores, ninguna de esas cosas jamás permanece la misma en cada individuo». ${ }^{51}$ ¿Qué es, entonces, lo que «creemos» que somos? Si nos hacemos conscientes de ese fluir al que se refiere la sacerdotisa platónica, si estamos más atentos a lo que sucede en nosotros, quizá seamos más serenos frente al fracaso, si sobreviene, y quizá no «rebotemos» hacia otra «fantasía vaporosa», irreflexiva y superficial, que trae un mal destino. A lo mejor podamos recibir heridos la experiencia, por supuesto, pero con la convicción profunda de una psyche que no es de mármol, y con la posibilidad de hallar otros sentidos en nosotros. Dejaremos de interpretar los acontecimientos desagradables de la vida de una manera fantástica, aérea, es decir, acomodada para que no comprometa lo que creemos que somos. En esos casos, por lo general, el responsable siempre es el otro. Por lo tanto, ciegos de nosotros, no nos permitimos ver algo propio que se revela, que requiere nuestra atención. $Y$ que nos advierte de una posible repetición.

Pero si hacemos "conciencia del fracaso», probablemente nos volvamos más compasivos con nuestros juicios, a nosotros y a los otros, si es que aún nos sentimos con el ímpetu de juzgar. Claro, a veces es insufrible no tener uno mismo de dónde asirse para poder soportarse. Y recordamos el drama filosófico de los mencionados interlocutores de Sócrates, que llegaban con algo al diálogo, con sus creencias y convicciones y, tras la jornada mayeútica, se iban sin nada. El camino, entonces, era la búsqueda, exi-

- y que nos han adjudicado-, con poca o ninguna reflexión, adquiere la solidez de un yeso ante nosotros mismos. Pero una vez que se la enfrenta pierde todo su poder y se desmorona, ocasionando en nosotros mucho dolor. Con todo, sabemos, que tras la caída de ese disfraz hecho de doxa, se abre el camino hacia la indagación que aspira —al menos- a lo verdadero.

50 Platón, Banquete, 208a. «kai oudepote hoi autoi esmen oude kata tas epistemas, alla kai mia hekaste ton epistemon tauton paschei». Las citas de los pasajes en griego son transcritas al latín sin acentos, siguiendo una de las opciones académicas en uso al respecto.

51 Platón, Banquete, 207e. «hoi tropoi, ta ethe, doxai, epithymiai, hedonai, lypai, phoboi, touton hekasta oudepote ta auta parestin hekasto». Recordemos a Aristóteles: «No hay nada que nos sea siempre agradable porque nuestra naturaleza no es simple ni perfecta», «ouk aei d' outhen hedy to auto dia to me haplen hemon einai ten physin», Ética a $\mathrm{Ni}$ cómaco, 1154b 20. 
gente y meticulosa, de eso que sí podía ser sólido en nosotros y podía ampararnos de todo desastre animado por el vaivén de lo ilusorio y aparente. Lo que para Sócrates era la verdad irrefutable, desde donde podía serenarse, era resultado de largo tiempo de excavaciones en sí mismo, que implicaban deshacerse de creencias sobrevenidas y generalmente falsas sobre las cosas y sobre sí mismo. Y ese saber, que tan celosamente distinguía del creer, ${ }^{52}$ se fundamentaba en toda la fuerza del argumento, y toda la intimidad y la emocionalidad quedaban reinterpretadas desde esa transformación lograda con la episteme. Sócrates pobló su alma de verdades, en un sentido fuerte, y desde allí se orientaba en los asuntos de la justicia o del amor. Pero la de Sócrates, es otra historia. Él fue el hombre «bueno» que ya no se afectaba por nada $a^{53}$; ni siquiera por los excesos de la multitud escandalosa que lo llevaron a la muerte. Con todo, parte de su grandeza está en que sus indagaciones nunca cesaron, y que sus hallazgos internos, su propio «cuidado del alma», fueron posibles en el diálogo, junto al otro. Ni siquiera Sócrates, en sus búsquedas por lo irrefutable, dejó de examinarse, de recorrerse, de preguntarse por sí mismo.

Sin embargo, las palabras de Diotima nos recuerdan al alma fluyente de Protágoras que nos dio la mano con su episteme tejida de aistheseis: cambiantes, variables, versátiles, de manera que no podemos ser nunca los mismos ni saber lo mismo de nosotros. ${ }^{54} \mathrm{Y}$, desde esta mirada, si somos aún

52 Platón, Apología de Sócrates, 21c y ss.; Gorgias, 454a y ss.

53 Platón, Lisis, 215a.

54 La episteme de Sócrates aspira a ser estable; la de Protágoras, por supuesto, no. El hallazgo de la verdad auténtica e irrefutable implica para Sócrates, como es sabido, un examen de las creencias y opiniones siempre cambiantes que, al no poder ser fundamentadas, no son verdaderas. Sin embargo, esa variabilidad y cambio de las percepciones y opiniones es lo que Protágoras admite como la misma episteme. Lo que ahora quiero señalar, a propósito de lo que nos ocupa, es que precisamente la conciencia de la condición cambiante de nuestras experiencias, en uno y otro caso, salvando sus grandes diferencias, es lo que nos permitiría enfrentar un suceso tan exigente como el fracaso. Para Sócrates eso cambiante no constituye lo verdadero, pues ha de ser estable y racionalmente fundamentado. Para Protágoras, sí, en tanto que lo verdadero es fluyente como la experiencia. Así, lo que ni siquiera es verdadero podría, stricto sensu, devastarnos; lo que es cambiante y pasajero, por su parte, podrá afectarnos, pero ese padecer será tan pasajero como la naturaleza misma de la experiencia. Ni en un caso ni el otro eso nos identifica con lo sucedido, ni se nos obliga a estar anclados a esa experiencia. O no es «verdadero» - lo que debería tranquilizarnos - o es pasajero como todo lo que deviene - lo que también ha de tranquilizarnos. Sócrates nos exigiría, por supuesto, antes de cualquier otra reflexión, una definición. Sabemos por los diálogos socráticos lo costoso de esa pretensión. (Cfr. la referencia a San Agustín y Wittgenstein p. 5, n. 15 y n. 16.). Y si la alternativa es la signifi- 
más radicales, podemos recordar al enigmático maestro budista Nagarjuna, ${ }^{55}$ quien argumenta a favor de la inexistencia absoluta de la mente, las percepciones o la conciencia —en realidad, de todo-, por su aparición inestable y condicionada mientras nos tranquiliza desde la paz del vacío, naturaleza última de todas las cosas. Sin embargo, y sin ser tan extremos como el budista, si somos capaces de argumentar que no somos los mismos siempre, como decía Diotima, ¿qué es lo que somos en un sentido definitivo y definitorio que no ha de someterse nunca a crítica y examen, como exigiría Sócrates? Desde la conciencia de ese fluir de experiencias que nos acontecen, a las que no debemos apegarnos porque su naturaleza es no permanecer, como lo afirmó Heráclito, Protágoras y también Buda, quizá nos sea posible domesticar un dolor tan fuerte como el del fracaso, pues no es fácil desapegarse de lo que uno cree que es. El trabajo interior más complejo probablemente sea ese reajustarse uno mismo tras la mala experiencia, ese encuentro con algo íntimo que desconocíamos, que pide ser reconocido y que, si hacemos conciencia, no deberíamos ignorar. "Las cosas son - escribe Wilde- también en su esencia lo que queremos hacerlas. Una cosa es según la manera como la miremos». ${ }^{56}$ Esto lo hubiese podido decir también Protágoras. Así, desde esta perspectiva, tenemos la posibilidad, incluso la gracia, de hacernos cada vez, de hallarnos cada vez, de poder dejar de ser Saulo para convertirnos de San Pablo; de poder ser la Perséfone que regresa a la luz del verano después de su rapto al infierno; de ser y aceptar lo que deviene en nosotros, dándole su justa medida.

Si tan sólo aprendiéramos la antigua lección de Heráclito del fluir indetenible de las cosas, de aquel decir profundo que como un trueno rugía «la physis de cada día es una [y la misma]», ${ }^{57}$ pues la naturaleza de todo lo que acontece es la misma, quizá el dolor del fracaso se disiparía como todo lo que está en constante devenir. Si lográramos hacer carne aquella verdad de Maestro Eckhart, que nos recuerda que nada nos pertenece, ni el alma ni la madre ${ }^{58}$ tendríamos menos apegos a esas versiones triunfalistas y maravi-

cación que otorga el uso y la consideración cambiante de lo que «somos», Diotima — sin llamar a lo cambiante episteme, junto a posturas incluso más extremas, nos permiten valorar la naturaleza fluyente, corruptible, temporal, de las experiencias que nos afectan.

55 Nagarjuna: Estrofas acerca de la esencia del surgimiento condicionado, V, Buenos Aires, Las Cuarenta, 2012: 114 y ss.

56 Op. cit., p. 575.

57 «Physis hemeras hapases mia», frag 106. Cfr. Markovich, op. cit., p. 81.

58 Maestro Eckhart, Ecos de la edad media..., Bogotá, Norma, 1998, p. 188. 
llosas de nosotros mismos. A lo mejor tendríamos más espacio para la aceptación del duro fracaso, que puede venir preñado de alguna chispa sapiente, y de la más preciosa de las virtudes, la humildad.

El hacer «conciencia», como sugiere López Pedraza, no es un ejercicio fútil del alma, por el contrario: puede salvarnos de la repetición de, por lo menos, otro fracaso. Sabemos de quienes viven toda su vida de fracaso en fracaso, haciendo gala de la repetición escabrosa que denuncian desde la antigüedad mitos, poetas, filósofos y religiones. No deja de ser interesante lo creativas que pueden sus «excusas», sin saberse presa ciega de procesos cíclicos y siempre parecidos. Por tanto, sin haberse dado el tiempo de haberlos saboreado y haber podido decir: no me gusta. Son espejo de lo que significa no haber hecho contacto con uno mismo, de no examinar lo que conduce por el camino aterrador de vivir muchas veces lo mismo con ropajes diversos. A veces son excusas creativas, pero sin la menor hondura. El secreto, sin embargo, siempre está en uno: «Necesito decirme a mí mismo - escribe Wilde - que tengo yo la culpa de todo, que nadie se aniquila sino por su propia voluntad... Si terrible fue lo que el mundo me hizo, mucho más terrible ha sido el daño que me he causado a mí mismo». ${ }^{59} \mathrm{La}$ mirada, desde Delfos hasta hoy, es siempre hacia uno mismo. Hacer conciencia, más aún, conocernos a partir de lo sucedido, puede salvarnos de ese ciclo infernal de fracasos repetidos.

Y esto expide nuevamente un profundo aroma socrático-platónico. En efecto, ese interesante sentido de «salvación» de las repeticiones, lo hallamos en el enigmático «mito de $\operatorname{Er}{ }^{60}$ donde Sócrates nos dice que sólo con la filosofía podremos salvarnos de los ciclos repetitivos de vidas escogidas desde el mero hábito o las falsas creencias. Eso implica, por supuesto, un filosofar socrático que expulsa de nosotros la falsedad que nos hace errar. Ese es un proceso filosófico arduo y complejo, que impide de todas las formas posibles que escapemos de lo que guardamos en nosotros. La vitalidad de los diálogos socráticos evita que nos petrifiquemos en lo que creemos que somos. En el mito, la filosofía nos salva de los cantos seductores del pasado que entonan Láquesis y las Sirenas ante las almas que van a decidir la nueva vida que les espera; nos salva de la vida irreflexiva que se repite desde el rechazo a experiencias vividas —otra

59 Op. cit., p. 529.

60 Platón, República, 614b y ss. Cfr. L. Rojas Parma, «Decidiendo la vida: el mito de Er de República, de Platón», Thémata, Revista de Filosofía, 53 (2106). 
forma de repetición; nos salva del olvido absoluto del pasado, mientras nos permite que la nueva vida sea elegida desde lo justo y lo bueno. Sócrates dice que, con la filosofía, atravesaremos esos lugares de la muerte, y saldremos bien librados de las vidas que se repiten. Eso es de lo que nos tenemos que «salvar».

Repetir, reemplazar, eso nunca es bueno.

Pero para no repetir, hay que saber qué no hemos de repetir y por qué. Es por ello que lo vivido hay que reflexionarlo, explorarlo, saberlo, saborearlo; y, sabido, dejarlo ir. Es por ello que no debemos pasar por la vida evadiendo, sepultando, sin examinarnos, como diría Sócrates, haciendo de la existencia un paso superficial que trivializa las experiencias e impide toda reflexión. Wilde ha dicho, con razón, que la superficialidad es el más grave de los vicios. ${ }^{61}$ Ahí se urde la condena de la repetición. Y ese suele ser un camino amigable para el fracaso. Por eso hablamos de transformación interior; del fracaso como esa difícil ocasión en la que es posible hacerlo diferente. Es en este sentido que una vida sin asombro, sin pensamiento, es una vida sin Eros. Así, una vida pobre. Decir, con Sócrates, que una vida sin examen no merece la pena ser vivida, es lo mismo que decir que una vida sin Eros, tampoco.

Cuando López Pedraza afirma que «la demanda de triunfo... nos impele a la repetición», sostiene también que la «conciencia del fracaso» es la que podría salvarnos de otros fracasos. A esto, he dicho, ha de acompañarlo el asombro reflexivo de la filosofía. Su disertación culmina con el poema Fracaso, de Rafael Cadenas. ${ }^{62}$ Poema doloroso, escrito como con el hollín del Hades, que arrasa con cualquier vestigio de vanitas o bybris que pueda esconder el alma, mientras nos enfrenta con la crueldad de lo que haya sucedido. Allí hallamos, con la fuerza llameante de un dios hindú, un agradecimiento profundo al fracaso, al horror que a veces nos brinda la vida, a la transformación de la que somos capaces y que nos embellece con la humildad ganada. Así, en uno de sus versos, dice el poeta al fracaso: «Me has conducido de la mano a la única agua que me refleja». Y entonces nos recuerda la imagen del otro que se vuelve nuestro espejo, y cuya aparición en la vida a través del amor se hace nuestro reflejo. En efecto, una importante versión del amor platónico, contada a través de un mito que narra Aristófanes en el Banquete, nos remonta al amor como un reencuentro

61 Op. cit., p. 571.

62 R. Cadenas, 2009, pp. 43-44. 
con uno mismo. ${ }^{63}$ La historia alude a los amantes arrancados de sí mismos por la bybris de otros tiempos. Fueron inicialmente un solo ser, redondo y, con ello, perfecto; sin embargo, por querer ser como los dioses, por no reconocer $s u$ propia condición de perfección, el ser fue castigado por Zeus y dividido en dos. Así, tras la ruptura, los amantes quedaron sufrientes y divididos, como unos symbola - «partes», «mitades» exclusivas que se pertenecen- a la espera de un Eros «terapéutico» que les permitiera encontrarse nuevamente. Cuando eso ocurría, cuando Eros «terapéutico» auxiliaba a los hombres en su reencuentro, los amantes no sabían por qué se reconocían y se amaban; por qué no podían estar ni un momento separados; desconocían que, en realidad, formaban parte del mismo ser, y que por eso sus almas anhelaban secretamente volver a aquella unidad perdida. Pero todos sabemos que lo que ha sido fracturado, ya no regresa a su perfección inicial. La torpeza, la bybris, dice la historia, termina con esa época feliz y perdida en el pasado de los seres humanos. De cada uno de nosotros. Ese deseo de los amantes de hacerse uno, nunca se cumple; ocurre momentáneamente en los éxtasis amorosos, pero el drama de la dualidad es inquebrantable.

Con todo, es el único amor que conocemos, pues no sabemos de esa historia del pasado y, por lo tanto, tampoco sabemos nada de nosotros. Y esto, socráticamente hablando, es una suerte de pecado. Así, lo que realmente ocurre es que terminamos amándonos a nosotros mismos, $r e-$ pitiéndonos, repitiendo el pasado; pues aquel que despierta el amor en nosotros es nosotros. Narciso sabía poco o nada de sí mismo... sólo veía su reflejo en el agua; y de tanto amor a esa imagen lo vimos fallecer. Los amantes de Aristófanes no fallecen; en realidad, si se reencuentran serán muy afortunados. El problema, sin embargo, como lo deja ver la incisiva Diotima, ${ }^{64}$ es que encontrarse a uno mismo en otro, el ver en el otro el propio reflejo — sin saberlo, por supuesto—, en medio de esa repetición que nada sugiere que sea «buena», no significa que hemos hallado algo que sea digno de amarse. Bien vistas las cosas, puede ocurrir incluso lo contrario: encontrarnos con el más rotundo fracaso. El Eros «terapéutico» nos permite el reencuentro con lo que es igual a nosotros, es cierto; pero ese therapeno puede significar, en realidad, llevarnos «de la mano a la única agua que me refleja». Y lo que me refleja a mí puede ser la som-

63 Platón, Banquete, 189c y ss. Cfr. L. Rojas Parma, «El amor del reencuentro: Aristófanes en el Banquete, de Platón»., La Lámpara de Diógenes, 26-27 (2014).

64 Platón, Banquete, 205d. 
bra del fracaso. El verso de Cadenas, como lo que nos deja ver Platón, es muy duro: de la mano, con Eros, somos conducidos a la única agua que nos refleja. Aristófanes decía que éramos como symbola tras el desgarre; esto quiere decir que sólo un symbolon, una mitad, «calza» con nosotros. Esto luce como un fatum, pues sólo hay «una única agua que me refleja». Y si las Moiras no fueron dóciles con mi destino, mi symbolon, el agua que me refleja, podría ser el fracaso — en realidad, nada lo impide.

Y si bien es duro, no dejemos pasar que el Eros del que habla Platón en el mito es un Eros «terapéutico». Y es el mismo Platón, a través de Diotima, el que nos deja sospechar que esa «curación» erótica podría implicar una experiencia de fracaso. La sacerdotisa dice que sólo estaríamos dispuestos a unirnos a lo agathon on, a lo «realmente bueno»; pues eso es, en tanto que bello, lo unico amable. En realidad, los hombres estarían dispuestos a cortarse las manos y los pies, si les pareciese que son malos. ${ }^{65} \mathrm{Y}$ con esto alude, por supuesto, a que los amantes del mito son «partes» del mismo ser que quieren refundirse en la unidad. Así, la pregunta que nunca se hace Aristófanes es: ¿qué sucede si ese reencuentro de amantes «verdaderos» — symbola - no tiene final feliz? Mientras, Diotima permite que nos preguntemos: ¿y qué impide que suceda un desastre? ¿Sabemos tanto de nosotros que nos sabemos «bellos» $\mathrm{y}$ «buenos» como para amarnos en otro? La respuesta platónica, por supuesto, es «no»: lo bello y lo bueno - lo que realmente se ama- son una episteme que implica caminos y esfuerzos de muy largo aliento, y para muy pocos. Lo importante ahora, sin embargo, es la suprema lucidez de llamar «terapéutico» a un amor que nos puede llevar por los suburbios del fracaso; de insinuar que en ese padecer puede haber sanación. La mirada que exploramos es enfrentar el padecimiento, ciertamente, pero para hallar la chispa sanadora hacia una aurora. «Cierto que me enseñaste con dureza ¡y tú mismo traías el cauterio! — dice Cadenas- Pero también me diste la alegría de no temerte; Me has hecho humilde, silencioso y rebelde». ${ }^{66}$

La terapia del fracaso, se nos devela. La terapia del fracaso del amor, que nos permite entrever el mito de un Eros «terapéutico».

65 Platón, Banquete, 205d-206a.

66 «La desventura ofrece posibles misericordias pero hay manías propias de los vencidos». M. Vestrini, «La niebla», en Esta es una buena máquina, Caracas, Letra muerta, 2015. 


\section{3. "AURORA»}

Alexandre Jollien, en un conmovedor texto sobre el abandono, sostiene que lo que resulta hermoso de la vida de Cristo, viéndola desde el punto de vista humano, es que en ella «existe el fracaso». «La cruz, para mí —escribe el autor-, es el punto cero de la esperanza. Jesús fracasó totalmente en la cruz. Todo falló... Es el punto cero de la vida humana, no hay esperanza, y aun así este punto cero deviene fundamento de salvación». ${ }^{67}$ Ese "punto cero» de la cruz aunque muerte, es la posibilidad de la vida; y si deviene salvación es porque desde allí, donde no ha quedado ni la esperanza aquella de Pandora, es posible la resurrección, la transformación interior, la posibilidad de incorporarnos de un modo distinto. Y lo distinto quiere decir, no repetirse. Ni siquiera Cristo regresa ante sus discípulos de la misma manera. Y ya Cristo sabía lo que puede enseñar el fracaso: a ser compasivo, a perdonar el agravio, y a ser humilde para no juzgar al otro que aún busca su camino. Pero la resurrección, con la valentía de la entrega y de hallar otros sentidos en uno, supone una travesía muy dolorosa que los cristianos llamamos "pasión». El abandonarse al fracaso, a la crucifixión, está custodiado por la vida apasionada que, con sabor de sangre, sabe que va a enfrentar la pena. Hay hondos procesos de «estaciones» que se cumplen en la vida, rebosantes de pasión, cada una, que han de saborearse, con la sal del sudor y las lágrimas, para vivirlas y saberlas en un sentido profundo, como se sabe la herida. Porque allí está la vida; y porque allí está la chispa de la transformación, de la posibilidad, de la resurrección. De ese "punto cero» de la vida hemos estado hablando; la enseñanza de Cristo fue salir del sepulcro. Bajo la pena de su pasión, había tierra sagrada. Nosotros, con menos de su fuerza y su humildad, por supuesto, desde el punto cero que nos toque vivir, tras la reflexión exigida y el sentido hallado en lo sucedido, quizá no logremos una resurrección, pero sí podemos esperar, pacientes, la aparición serena de la Aurora. Dice un verso del Rig Veda: «Ha venido brillando como una mujer joven; / a todo ser viviente ha puesto en movimiento. / Ya el fuego debe ser encendido por los hombres. / La Aurora ha hecho la luz, expulsando a la tiniebla». ${ }^{68}$

Las imágenes son sugerentes, eróticas, rebosantes de vida y esperanza. La mujer joven destrona a las tinieblas; permite que los hombres encien-

67 A. Jollien, Pequeño tratado del abandono, Barcelona, Paidós, 2013: 68-69.

68 «A la Aurora», en Himnos del Rig Veda. Buenos Aires, Las Cuarenta, 2014, VII, 77 (593), v 1, p. 152. Trad. Fernando Tola. 
dan sus fuegos y haya movimiento. Pone fin a una oscuridad inmóvil e infértil. Es hora del cultivo, de la salida lenta de la caverna, de serenarse con el brillo de la mujer que vitaliza todo lo que permanecía en la penumbra. Esa es la Aurora, la dueña del intermedio entre la retirada de la noche y el arribo del sol. Esa es la luz que podemos contemplar, desde las honduras de nuestro pesar, si hemos logrado la transformación que inicia «la llama purificadora del dolor». ${ }^{69}$ Esa es la recompensa de la aceptación, de no sepultarnos, de habernos detenido en la meditación, de haber estado atentos al asombro, y de haber logrado hallazgos en nosotros. Quizá la imagen de la resurrección sea muy exigente, y por ello el asomo de la Aurora sea más modesto, no tan definitivo y más enigmático. Y este aspecto misterioso de la Aurora, intermedio, encuentro sereno de los opuestos, exige un poco de nuestra atención. Es tan complejo y enigmático, he señalado antes, como el metaxy de Platón; ${ }^{70}$ y puede sernos útil recordarlo, para aproximarnos a esta Aurora que se devela tras la noche oscura del fracaso. En otro verso del Rig Veda, dice el poeta: «Así como la Aurora es puesta en marcha, para que surja el sol, / así la Noche se ha retirado ante la Aurora». ${ }^{71}$

Ella es el intermedio entre la salida del sol y de la huída de la noche. Aún no es sol y ya no es noche. El «intermedio» platónico tiene un aire de familia con la imagen de la Aurora. En Banquete, diálogo en que voy a concentrar estas últimas reflexiones, ${ }^{72}$ encontramos a Eros en medio (en meso) de lo humano y lo divino. No es un mortal, tampoco es un dios -es un daimon - , que cumple funciones maravillosas como comunicar a los dioses y a los hombres, llevar sus mensajes, inspirar a los adivinos en sus aciertos y a los sacerdotes en sus ritos. Como si fuera poco, Eros, desde ese lugar intermedio que ocupa, une lo distinto, pues permite un continuum en todo lo que existe. ${ }^{73}$ Eros está cohesionando el kosmos desde muy antiguo. Los dioses y los hombres no se comunican directamente: es el amor

69 Schopenhauer, op. cit., p. 53.

70 Platón, Lisis, 220d; Gorgias, 467e; 468a; República, 498a; 511d; 583c; Banquete, 202a; Fedro, 230a; Parménides, 152c; 161d. Cfr. Banquete, 202e; 203 a.

71 «A la Aurora», en Himnos del Rig Veda, I, 113, v 1, p.66. Escribe Miyó Vestrini: «Hay en $\mathrm{Al}$ día siguiente un poder. Hay en algunas imágenes de $\mathrm{Al}$ día siguiente un poder que ni críticos, ni publicistas, ni políticos, podrán entender jamás. Es el poder de los que no tienen nada, salvo la dulce espera del final. Son la nada silenciosa». M. Vestrini, Esta es una buena máquina..., 2015, Segunda Parte (edición sin número de páginas).

72 Platón, Banquete, 202a-204c.

73 Platón, Banquete, 202e; Gorgias, 508a. 
lo que hace posible que se escuchen y sepan unos de otros. El amor humaniza y diviniza. Adivinar al otro es un acto profundamente erótico; el ritual sagrado del sacerdote, el ritual sagrado de lo que hacemos con liturgia, es un acto erótico. Allí los dioses nos hablan. El amor es su vocal. Ese daimon ingenioso, dice Diotima en su mito, ${ }^{74}$ pleno de recursos, hechicero, fascinador, pero siempre pobre, durmiendo en las orillas y a la caza de lo bello, es el hijo de Poros y Penía, el lugar en que convergen los contrarios. Así es la Aurora. Embellecida como la mujer que pone en marcha la luz, que hace a los hombres encender el fuego, pero que aún no es el sol y que despide lo oscuro. En ese metaxy, ese estar en medio, si lo consideramos ahora desde República, hallamos el «reposo» (besychian) -intermedio entre el dolor y el placer-,${ }^{75}$ lugar que en Banquete ocupa lo erótico y donde ocurre el aparecer maravilloso de la Aurora. El amor, la Aurora, se rodean de un aura de sosiego. Y si a alguna salvación nos hemos referido, después de tanto fracaso dicho, no puede ser mejor invocada que como un reposo. Bello como una Aurora y lleno de recursos como el amor. ${ }^{76}$

Finalmente, oímos decir a Diotima que Eros muere y renace constantemente: «unas veces florece y vive... y otras muere, pero recobra la vida de nuevo gracias a la naturaleza de su padre». ${ }^{77}$ Así, el suceder inevitable de la Aurora, también se nos devela erótico: «una tras otra, sin cesar - dice el himno-, brilló en el pasado la divina Aurora. Generosa ha brillado hoy y brillará en los días por venir». ${ }^{78}$ Por tanto, "Ya vienen otros hombres que han de contemplar nuevas Auroras». ${ }^{79}$

Que haya muchas Auroras, como muchos amores, sugiere que muchas noches oscuras han de sobrevenir. Que los procesos interiores no son estáticos. Recordemos lo dicho: ¿qué cosa de mármol es la que llevamos con nosotros que no puede ser examinada? Sócrates nos enseñó que vamos

74 Platón, Banquete, 203b-204b.

75 Platón, República, 583 c y ss.

76 Escribe López Pedraza: «Cuando nos referimos a conciencia del fracaso, nos estamos refiriendo a estados medios y lentos del alma: al anima media natura, ese estado donde no hay triunfalismos, sencillamente porque hay un alma o psique que es consciente... pero también es un alma a la que no quebranta el otro extremo: el fracaso hecho realidad», op. cit., p. 129.

77 Platón, Banquete, 204d-e.

78 «A la Aurora», Himnos del Rig Veda, I, 113, v 13, p. 69.

79 «A la Aurora», Himnos del Rig Veda, I, 113, v 11, p. 69. La conciencia del fracaso, dice López, «es evasiva, viene y se va... media y oscura, cuyo sitio es el umbral y su luz crepuscular», op. cit., p. 129. 
haciendo alma mientras dialogamos nuestras convicciones, que las búsquedas suelen no tener un punto definitivo de llegada, aunque se aspire a eso; que la vida que vale la pena vivir, entonces, es una vida filosófica. Y si nos toca volver a la noche oscura, ya no seremos los mismos. Si hemos hecho conciencia, quizá Atenea nos proteja de otra repetición; si hemos hallado la chispa filosófica en el asombro que surge en la penumbra, será la filosofía la que nos proteja.

A la emocionalidad que activa el fracaso, como aisthesis que nos envuelve en una episteme temblorosa y cambiante, que nos hace saber de nosotros, si hemos decidido hacer alma con ello, podemos decir, con $\mathrm{Ca}$ denas, «gracias». "Gracias por la riqueza a que me has obligado. Gracias por construir con barro mi morada. Gracias por apartarme. Gracias».

Comencé este ensayo de la mano de Dioniso. Dios de estos territorios divinos de la noche y las tristezas. Pero también del baile y el desenfreno. Dioniso, él mismo un «intermedio» entre lo masculino y lo femenino, ${ }^{80}$ pide que le concedan su sitial olímpico. Por ello, quizá lo oportuno sea concluir recordando las conmovedoras escenas de los viejos sabios Cadmo y Tiresias, en Bacantes, cuyos años no les impidieron vestirse de devotos de Dioniso, para ir a bailar con las mujeres, golpear la tierra con el tirso y beber el vino del dios. Tras confesarse la juventud que aún sienten para entregarse a las danzas, se van al monte con la bella torpeza de la vejez que aún va al encuentro de la vida. ${ }^{81}$ La sabiduría que encarnan Cadmo y Tiresias, es la que sabe que hay que reconocer la noche oscura del alma, con su frenesí y su llanto, y que hay que rendirle culto al dios de lo que nos duele, de cuando en cuando.

Y si es Dioniso el que nos permite cerrar el drama, entonces las palabras finales de Zorba, el griego, uno de los personajes dionisíacos más hermosos del cine, resumen con finura lo que podamos concluir aquí: ahogado en una risa dionisíaca, tras la catástrofe ocurrida con la construcción, dice a su joven amigo: «¿ has visto un desastre más espléndido?» Y sin prestar ya importancia al fracaso acontecido, se entrega al baile que conecta con la conciencia de la vida, con la locura que Zorba reclama, mientras se eleva sobre todo sufrimiento. A diferencia de Schopenhauer, ese elevarse sobre el sufrimiento no renuncia a la voluntad de vivir; por el contrario, lo devuelve al corazón de la vida.

80 Eurípides, Bacantes, vv 230-240; 490.

81 Eurípides, Bacantes, vv 185-190. 
Este movimiento del alma es expresión, como en Cadmo y Tiresias, de muchas penas sufridas, de mucho volver tras la tiniebla, de contemplar muchas Auroras.

Quizá el camino de los antiguos maestros de Oriente o de Platón, sea lo único que detenga la circularidad de la vida, que siempre se encuentra consigo misma. «No importa por dónde empiece — dijo el temible Parménides-, siempre llegaré al mismo lugar». ${ }^{82}$

\section{REFERENCIAS BIBLIOGRÁFICAS}

Barros Gutiérrez, José, 1980, «El pensamiento de Protágoras». En Protágoras y Gorgias, testimonios y fragmentos. Barcelona, Orbis: 17-40.

CappelletTi, Ángel, 1987, Protágoras, naturaleza y cultura. Caracas, Biblioteca Nacional de la Historia.

CARPENTER, Thomas y Christopher FARAOne, comps., 1993, Masks of Dionysus. Cornell University Press.

Colli, Giorgio, 2000, El nacimiento de la filosofía. Barcelona, Tusquets.

CORNFORD, Francis M., 1992, La teoría platónica del conocimiento. Barcelona, Paidós.

Corominas, Joan, 1973, Diccionario etimológico de la lengua castellana. Madrid, Gredos.

Cruz, Manuel, 2013, Amo, luego existo. Buenos Aires, Eudeba.

Detienne, Marcel, 1998, Dionysos mis à mort. Gallimard, Saint-Amand (Cher).

Detienne, Marcel, 1997, Dioniso a cielo abierto. Barcelona, Gedisa.

DupréEL, Eugène, 1948, Les sophistes. Neuchâtel, Editions Du Griffon.

EgGers LAN, Conrado, 1995, El sol, la linea y la caverna. Buenos Aires, Colihue.

GADAMER, Hans G., 1999, Verdad y método. Fundamentos de una hermenéutica filosófica. Salamanca, Sígueme.

GadAmer, Hans G., 2001, El inicio de la sabiduría. Barcelona, Paidós.

García-Baró, Miguel, 2004, De Homero a Sócrates. Salamanca, Sígueme.

Hillman, James, 2005, El pensamiento del corazón. Madrid, Siruela.

Himnos del Rig Veda. Buenos Aires, Las Cuarenta, 2014.

Hobbes, Thomas, 1978, Leviathan. Glasgow, William Collins.

82 «Hoppothen arxomai- tothi gar palin hixomai authis». Frag. 289. G. Kirk, Raven, J., Schofield, M.: Los filósofos presocráticos, Madrid, Gredos, 1987. La traducción de esta edición: «Me es igual por dónde comience; pues volveré de nuevo allí con el tiempo». 
Humbert, Jean, 1995, Sócrates y los socráticos menores. Caracas, Monte Ávila.

Jollien, Alexandre, 2013, Pequeño tratado del abandono. Barcelona, Paidós.

KeréNYI, Károly, 1998, Dionisos, raíz de la vida indestructible. Barcelona, Herder.

Kirk, Geoffrey S., John Earle Raven y Michael Schofield, 1987, Los filósofos presocráticos. Madrid, Gredos.

LÓpez-Pedraza, Rafael, 2000a, Ansiedad cultural. Caracas, Festina Lente.

López-PedrazA, Rafael, 2000b, Dionisos en el exilio. Caracas, Festina Lente.

Luri Medrano, Gregorio, 1998, El proceso de Sócrates. Madrid, Trotta.

MANSFeld, Jaap, 1981, «Protagoras on Epistemological Obstacles and Persons». En G. Kerferd, comp., The sophists and their legacy (International Colloquium on Ancient Philosophy (4th: 1979: Bad Homburg vor der Höhe, Germany). Wiesbaden, F. Steiner: 38-53.

Markovich, Miroslav, 1968, Heraclitus, editio minor. Mérida, Universidad de Los Andes.

Melero Bellido, Antonio, 1996, Sofistas, testimonios y fragmentos. Madrid, Gredos.

NieTszCHE, Friedrich, 1981, Aurora. México, Editores Mexicanos Unidos.

Nussbaum, Martha, 1995, La fragilidad del bien. Madrid, Visor.

OтTO, Walter F., 1997, Dioniso, mito y culto. Madrid, Siruela.

PAlacios, María Fernanda, 1984, Sabor y saber de la lengua. Caracas, Monte Ávila.

PATOČKa, Jan, 1991, Platón y Europa. Barcelona, Península.

Rojas-PARma, Lorena, 2016, «Decidiendo la vida: el mito de Er de República, de Platón», Thémata, 53 (2016): 31-62.

ROJAS-PARMA, Lorena, 2015, «Protágoras y el significado de aisthesis». Revista de Filosofía, 71 (2015): 127-149.

Rojas-PARma, Lorena, 2014, «El amor del reencuentro: Aristófanes en el Banquete, de Platón». La Lámpara de Diógenes, 26-27 (2014): 29-70.

RojAs-PARma, Lorena, 2011, «De la polis, la tradición y el buen juicio: el ciudadano democrático de Protágoras». Cuadernos UCAB, 9: 117-148.

Rojas-Parma, Lorena, 2005, «Acerca de aisthesis en el Teeteto de Platón», Apuntes (Caracas, UCV), 27: 38-51.

SCHLESIER, Renate, 1993, «Maenads as Tragic Models». En Th. Carpenter y Ch. Faraone, comps., Masks of Dionysus. Ithaca, NY, Cornell University Press: 89-114.

Schopenhauer, Arthur, 2013, Los dolores del mundo. Buenos Aires, Prometeo.

TAYlor, Anelise, 1959, Plato, the Man and his Work. New York, Meridian Books.

Untersteiner, Mario, 1967, I sofisti. Testimonianze e Frammenti. Milano, L. Negri. 
Vestrini, Miyó, 2015, Esta es una buena máquina. Caracas, Letra muerta.

Wilde, Oscar, 2004, De Profundis. Obras completas. Madrid, Santillana.

WitTGenstein, Ludwig, 2008, Investigaciones filosóficas. Barcelona, Crítica.

\section{Referencias a ediciones de fuentes clásicas}

Aristóteles, Ética a Nicómaco, Madrid, Centro de Estudios Constitucionales, 1985. Trad. M. Araujo, J. Marías.

Agustín de Hipona, Confesiones, Madrid, Biblioteca de Autores Cristianos, 1951.

Apolodoro de Atenas, Biblioteca mitológica. Madrid, Alianza, 1999.

Eurípides, Bacantes. Madrid, Gredos, 1982.

Eurípides, Ifigenia entre los tauros. Madrid, Gredos, 1982.

Eckhart, Maestro 1998, Ecos de la Edad Media. Treinta dias con un gran maestro espiritual. Bogotá, Norma.

Nagarjuna, Estrofas acerca de la esencia del surgimiento condicionado. Buenos Aires, Las Cuarenta, 2012.

Platonis Opera, J. Burnet, Clarendon, Oxford University Press, 1973. Tomos I-III.

Platón, Apología, Buenos Aires, Eudeba, 1998. Traducción de C. Eggers.

Platón, Ión, Madrid, Gredos, 1981. Trad. E. Lledó.

Platón, Lisis, Madrid, Gredos, 1981. Trad. E. Lledó.

Platón, Hipias Mayor, Madrid, Gredos, 1981. Trad. J. Calonge.

Platón, Laques, Madrid, Gredos, 1981. Trad. C. García Gual.

Platón, Protágoras, Madrid, Gredos, 1981. Traducción de C. García Gual.

Platón, Gorgias, Madrid, Gredos, 1999. Traducción de J. Calonge.

Platón, Banquete, Madrid, Gredos, 1997. Traducción de M. Martínez.

Platón, Fedro, Madrid, Gredos, 1997. Traducción de E. Lledó.

Platón, Teeteto, Barcelona, Ánthropos, 1990. Traducción de M. Balasch.

Platón, Parménides. Madrid, 1998. Trad. M. I. Santa Cruz.

Sexto Empírico, Esbozos Pirrónicos. Madrid, Gredos, 1993.

Sexto Empírico, Contra los profesores, Madrid, Gredos, 1997.

Sófocles, Antígona. Madrid, Gredos, 1982. 